\title{
Characteristics and outcomes of patients with COVID-19 admitted to hospital and intensive care in the first phase of the pandemic in Canada: a national cohort study
}

Srinivas Murthy MD, Patrick M. Archambault MD MSc, Anika Atique BSc, François Martin Carrier MD MSc, Matthew P. Cheng MDCM, Cassidy Codan BSc, Nick Daneman MD MSc, William Dechert Msc, Sarah Douglas BEng, Kirsten M. Fiest PhD, Robert Fowler MDCM MSc, Geraldine Goco BSN, Yusing Gu MD, Anne-Marie Guerguerian MD PhD, Richard Hall BScPharm MD, Jimmy M. Hsu MSc, Ari Joffe MD, Philippe Jouvet MD PhD, Laurel Kelly MSc(PT), Michelle E. Kho PT PhD, Rebecca J. Kruisselbrink MD MPH, Deepali Kumar MD MSc, Demetrios James Kutsogiannis MD MHS, François Lamontagne MD, Todd C. Lee MD MPH, Kusum Menon MD, Heather O'Grady BSc, Katie O’Hearn MSc, Daniel H. Ovakim MD MSc, Scott G. Pharand MPH BScH, Tyler Pitre MD MA, Riley Reel BSN, Brenda Reeve MD, Oleksa Rewa MD MSc, David Richardson MD MHS, Asgar Rishu MBBS, Gyan Sandhu BScH BScN, Shirley Sarfo-Mensah MPH, Ellen Shadowitz, Wendy Sligl MD, Joshua Solomon MSc, Henry T. Stelfox MD, Ashleigh Swanson, Hubert Tessier-Grenier, Jennifer L.Y. Tsang MD PhD, Gordon Wood MD; for the SPRINT-SARI Canada Investigators and the Canadian Critical Care Trials Group

Abstract

Background: Clinical data on patients admitted to hospital with coronavirus disease 2019 (COVID-19) provide clinicians and public health officials with information to guide practice and policy. The aims of this study were to describe patients with COVID-19 admitted to hospital and intensive care, and to investigate predictors of outcome to characterize severe acute respiratory infection.

Methods: This observational cohort study used Canadian data from 32 selected hospitals included in a global multisite cohort between Jan. 24 and July 7, 2020. Adult and pediatric patients with a confirmed diagnosis of COVID-19 who received care in an intensive care unit (ICU) and a sampling of up to the first 60 patients receiving care on hospital wards were included. We performed descriptive analyses of characteristics, interventions and outcomes. The primary analyses examined in-hospital mortality, with secondary analyses of the length of hospital and ICU stay.

Results: Between January and July 2020, among 811 patients admitted to hospital with a diagnosis of COVID-19, the median age was 64 (interquartile range [IQR] 53-75) years, 495 (61.0\%) were men, $46(5.7 \%)$ were health care workers, $9(1.1 \%)$ were pregnant, $26(3.2 \%)$ were younger than 18 years and $9(1.1 \%)$ were younger than 5 years. The median time from symptom onset to hospital admission was 7 (IQR 3-10) days. The most common symptoms on admission were fever, shortness of breath, cough and malaise. Diabetes, hypertension and cardiac, kidney and respiratory disease were the most common comorbidities. Among all patients, 328 received care in an ICU, admitted a median of 0 (IQR $0-1)$ days after hospital admission. Critically ill patients received treatment with invasive mechanical ventilation (88.8\%), renal replacement therapy (14.9\%) and extracorporeal membrane oxygenation (4.0\%); $26.2 \%$ died. Among those receiving mechanical ventilation, $31.2 \%$ died. Age was an influential predictor of mortality (odds ratio per additional year of life 1.06, 95\% confidence interval 1.03-1.09).

Interpretation: Patients admitted to hospital with COVID-19 commonly had fever, respiratory symptoms and comorbid conditions. Increasing age was associated with the development of critical illness and death; however, most critically ill patients in Canada, including those requiring mechanical ventilation, survived and were discharged from hospital.

chief concern over the first months of the coronavirus disease 2019 (COVID-19) pandemic was the capacity to provide care for acutely ill patients in hospitals and intensive care units (ICUs). The variability in outcomes of patients with COVID-19 internationally has been striking, with some reports describing ICU mortality in ranges between 40 and $90 \% .^{1-3}$ Systematic reviews including
Competing interests: See the end of the article.

This article has been peer reviewed.

Correspondence to: Srinivas Murthy, Srinivas.murthy @cw.bc.ca CMAJ Open 2021. DOI:10.9778/cmajo.20200250 
10000 patients worldwide show a combined ICU mortality of $42 \% .{ }^{4}$ Acute care features associated with mortality include health care resource use and availability, supportive care and specific treatment strategies. ${ }^{5,6}$

Canada has had more than 10000 hospital admissions for COVID-19 and 110000 confirmed cases as of July 15, 2020, the time of this data analysis. ${ }^{7}$ These hospital admissions have resulted in health system strain - particularly in acute care and long-term care homes; however, hospitals and ICUs have not been overwhelmed to the extent experienced in many other countries, ${ }^{1,8}$ perhaps owing to public health strategies that have included physical distancing and border closures, effective hospital-based infection prevention and control practices, early cessation of nonemergent care and luck.

Documenting the numbers and characteristics of patients with COVID-19 requiring hospital or ICU admission across Canadian hospitals is vital to facilitate comparison with other health jurisdictions and in preparation for future pandemic waves. We aimed to describe a representative population of patients with COVID-19 admitted to hospital and intensive care, and investigate predictors of outcome using a national pre-existing registry to characterize severe acute respiratory infection.

\section{Methods}

\section{Study design}

SPRINT-SARI (Short Period Incidence Study of Severe Acute Respiratory Infection) is a global, multisite observational cohort of patients admitted to hospital with severe acute respiratory infection. ${ }^{9}$ Data have been collected in Canada and across the world since 2016, establishing research infrastructure for pandemics to rapidly produce observational data. ${ }^{10}$

In January 2020, the case report form was adapted for COVID-19, and has been used, in conjunction with the International Severe Acute Respiratory and Emerging Infection Consortium (ISARIC) and the World Health Organization (WHO), around the world to describe clinical disease from COVID-19 across populations and inform policy globally. ${ }^{11-13}$ SPRINT-SARI is administered in Canada from Sunnybrook Research Institute with a global data repository coordinated by the University of Oxford, which included more than 100000 patients as of July 2020.

\section{Data sources}

Participating Canadian sites were recruited through convenience sampling, both through the Canadian Critical Care Trials Group, a national trials network, and through networks of the research team, and included both pediatric and adult hospitals across the country with both academic and community hospitals (Appendix 1, available at www.cmajopen.ca/ content/9/1/E181/suppl/DC1). There was no specific geographic targeting or specific sampling strategy employed. These data from Canadian hospitals are included in global data sets, including the relevant research tools such as case report forms; ${ }^{14}$ these data will also be included in global analyses that will be forthcoming.

\section{Participants}

The study population included all patients with a confirmed diagnosis of COVID-19 who were admitted to an ICU in study hospitals, as well as quota sampling of up to the first 60 patients admitted to hospital wards between Jan. 24 and July 7, 2020. This sampling strategy was meant to more comprehensively sample critically ill patients and to limit data collection by strained research and clinical teams during the first wave of the pandemic.

Data were collected on admission, daily and on hospital discharge, and included baseline demographic characteristics, comorbidities, interventions given and hospital outcomes. Data elements were standardized with global data collection efforts with ISARIC and the WHO to optimize international comparisons. ICUs were defined as per local practice, acknowledging that the capabilities and capacities of ICUs vary across hospitals. Comorbidities were defined by the treating clinicians as documented in patient charts. Patients were tested for severe acute respiratory syndrome coronavirus 2 (SARS-CoV-2) according to local practice, which was naso- or oropharyngeal swabs for polymerase chain reaction testing at all centres, and patients received treatment according to local standards of care.

\section{Statistical analysis}

The primary outcome measure was in-hospital mortality censored as of July 7, 2020. Secondary outcomes included duration of ICU and hospital stay. Unadjusted odds ratios (ORs) for mortality with baseline demographic characteristics, including age and comorbidities, were calculated by univariate analysis. Descriptive statistics included frequency analysis (percentages) for categorical variables, and means (standard deviation [SD]) or medians (interquartile range [IQR]) for continuous variables, depending on data distribution.

We performed logistic regression modelling for the primary outcome, using baseline age and sex as the adjusted variables based on data from other cohorts. Data were submitted and checked for errors by manual inspection and electronic range limits. We evaluated symptoms for pairwise comparisons. Patients still alive and in hospital at the time of censoring were not included in the outcome assessments. We used the Kaplan-Meier method to depict the probability of survival over the duration of follow-up and to generate survival curves, with bounds as $95 \%$ confidence intervals (CIs). Estimates for distribution of time-based variables were obtained through a $\gamma$ distribution fitted onto the observed data, accounting for unobserved outcomes, with estimation by a maximum likelihood procedure and CIs for the means and variances obtained by bootstrap. Confidence intervals and $p$ values reported reflect a 2 -tailed $\alpha$ level of 0.05 . Statistical analyses were performed in R. ${ }^{15}$

\section{Ethics approval}

This study was approved by local ethics boards, generally using a waiver of consent given the need to collect routinely 
available clinical data only, with no need for additional studyspecific diagnostic testing.

\section{Results}

From Jan. 24 until July 7, 2020, 811 hospital-admitted patients across 32 hospitals (4 academic pediatric, 13 community and 15 adult academic) were included in the analysis. Of these, 328 patients required admission to an ICU.

The median age of all patients was 64 (IQR 53-75) years, $495(61.0 \%)$ were men, $9(1.1 \%)$ were pregnant and 46 $(5.7 \%)$ were health care workers. A total of $26(3.2 \%)$ were younger than 18 years and 9 were younger than 5 years (Table 1), with 5 children being admitted to ICUs in participating children's hospitals.

Presenting symptoms are described in Figure 1; the most common symptoms on admission were fever (593/804, $73.7 \%)$, shortness of breath $(538 / 802,67.1 \%)$, cough (331/680, 48.6\%), fatigue or malaise (347/801, 43.3\%), and diarrhea (209/800, 26.1\%). Mapping symptoms into clusters revealed no clear patterns of symptoms, and less than $7 \%$ of patients presented without one of fever, shortness of breath, fatigue or cough. The median time from symptom onset to hospital admission was 7 (IQR 3-10) days.

Table 1, Figure 2, and Appendix 2, Supplemental Figure 2 (available at www.cmajopen.ca/content/9/1/E181/suppl/DC1) show the most common comorbidities, including diabetes, hypertension, and cardiac, kidney and respiratory disease. With regard to outpatient medications, 90 (11.1\%) patients were taking nonsteroidal anti-inflammatory drugs, $104(12.8 \%)$ were taking angiotensin-converting enzyme inhibitors and $122(15.0 \%)$ were taking angiotensin receptor blockers.

\section{Treatments}

Most patients received antibiotics (78.9\%) or oxygen $(74.2 \%)$. In total, $21.2 \%$ of patients received an antiviral agent, with oseltamivir, lopinavir-ritonavir, hydroxychloroquine and ribavirin being the 4 most commonly used; $18.6 \%$ of ward patients and $28.9 \%$ of ICU patients received systemic corticosteroids (Table 2).

Patients were admitted to ICU a median of 0 (IQR 0-1) days after admission to hospital, with $58.8 \%$ on the first day of hospital admission and $75.9 \%$ of patients within the first 2 days

Table 1: Characteristics of patients with coronavirus disease 2019 admitted to hospital and intensive care

\begin{tabular}{|c|c|c|}
\hline \multirow[b]{2}{*}{ Characteristic } & \multicolumn{2}{|c|}{ No. $(\%)^{*}$} \\
\hline & $\begin{array}{l}\text { All patients admitted to hospital } \\
\qquad n=811\end{array}$ & $\begin{array}{l}\text { Patients admitted to ICU } \\
\qquad n=328 \dagger\end{array}$ \\
\hline Age, yr, median (IQR) & $64(53-75)$ & $65(54-72)$ \\
\hline \multicolumn{3}{|l|}{ Age, yr } \\
\hline$<19$ & $26(3.2)$ & $5(1.5)$ \\
\hline$>70$ & $40(4.9)$ & $23(7.0)$ \\
\hline Sex, female $\ddagger$ & $315(38.8)$ & $105(32.0)$ \\
\hline \multicolumn{3}{|l|}{ Comorbidities } \\
\hline Hypertension & $361(44.5)$ & $149(45.4)$ \\
\hline Diabetes & $203(25.0)$ & $90(27.4)$ \\
\hline Cardiac disease & $171(21.1)$ & $67(20.4)$ \\
\hline Chronic kidney disease & $102(12.6)$ & $67(20.4)$ \\
\hline Liver disease & $30(3.7)$ & $14(4.3)$ \\
\hline Asthma & $90(11.1)$ & $38(11.6)$ \\
\hline Smoking & $37(4.6)$ & $16(4.9)$ \\
\hline Obesity & $23(2.8)$ & $15(4.6)$ \\
\hline AIDS/HIV & $8(1.0)$ & $3(0.9)$ \\
\hline Malignant neoplasm & $28(3.5)$ & $13(4.0)$ \\
\hline Pregnancy & $12(1.5)$ & 0 \\
\hline $\begin{array}{l}\text { Time from symptom onset to hospital } \\
\text { admission, } d \text {, mean } \pm S D\end{array}$ & $12.5 \pm 8.8$ & $15.0 \pm 9.3$ \\
\hline Overall mortality & $166(20.5)$ & $86(26.2)$ \\
\hline
\end{tabular}




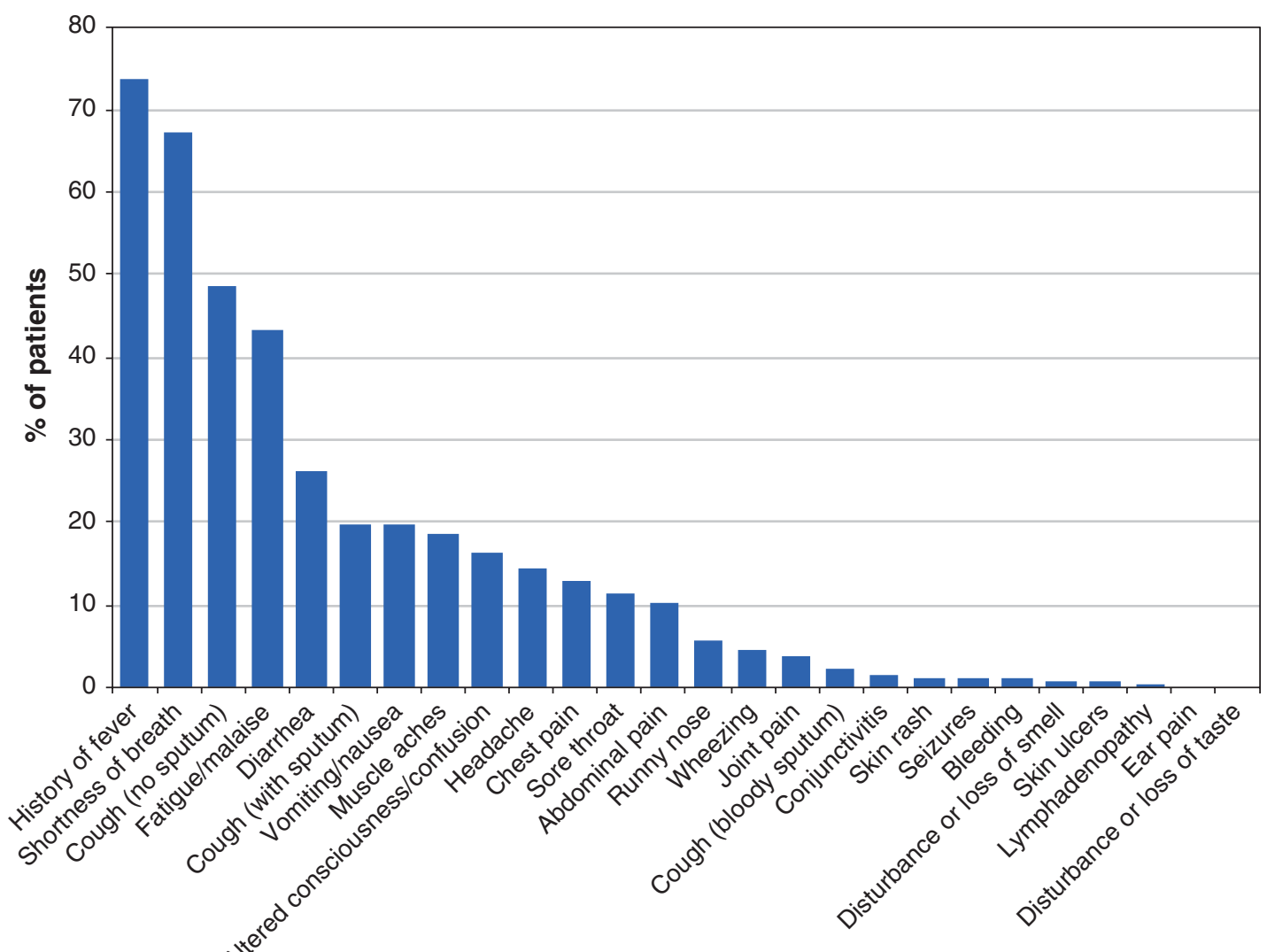

Symptom present

Figure 1: Presenting symptoms seen on admission among 811 patients admitted to hospital with coronavirus disease 2019.

of hospital admission. Appendix 2, Supplemental Figure 1 shows length of stay by sex, age and admission location. Appendix 2, Supplemental Figure 3 shows the density function of time to outcome (death or recovery) in included patients.

\section{Outcomes}

As of reporting, 166 patients had died (20.5\%) (Figure 3). Of the 328 patients admitted to an ICU, 86 (26.2\%) had died, with 20 patients $(2.5 \%)$ still admitted to hospital as of July 7 , 2020. Seven deaths occurred in patients younger than 50, with the youngest death at age 27 (Table 3). Each additional year of age was independently associated with death on univariate analysis (OR 1.06, 95\% CI 1.03-1.09). A total of 80 hospital-admitted patients died without having been admitted to an ICU (48.2\% of all deaths), suggesting limitations on care were present.

Mortality among patients who received invasive mechanical ventilation was $31.2 \%, 69.2 \%$ among patients receiving ECMO and $46.9 \%$ among those who received renal replacement therapy during their ICU course. Patients who died were also more likely to have comorbidities (Table 3), including hypertension (OR 2.52, 95\% CI 1.70-3.78), chronic pul- monary disease (OR 3.11, 95\% CI 1.93-4.99), chronic renal disease (OR 2.31, 95\% CI 1.43-3.69), diabetes (OR 2.28, 95\% CI 1.50-3.45), or a malignant neoplasm (OR 2.31, 95\% CI 1.18-4.42). Multivariate modelling, adjusting for age and sex, showed that chronic pulmonary disease (OR 3.45, 95\% CI 1.13-10.73) and chronic renal disease (OR 3.88, 95\% CI 1.15-13.8) were the comorbidities strongly predictive of inhospital mortality.

\section{Interpretation}

We report on a large cohort of Canadian patients admitted to hospital with COVID-19 (representing about $8 \%$ of all admitted patients in Canada at the time [total 10 728] and $14.6 \%$ of all ICU admissions [total 2247] ${ }^{7}$ ). We describe demographic data, interventions and clinical outcomes of patients. The most common presenting symptoms were fever and cough, and the most common comorbidities were hypertension, diabetes and chronic cardiac disease. Among patients admitted to hospital with COVID-19 who received intensive care, mortality was $26 \%$, similar to reports from other regions of the world..$^{1,16-19}$ 


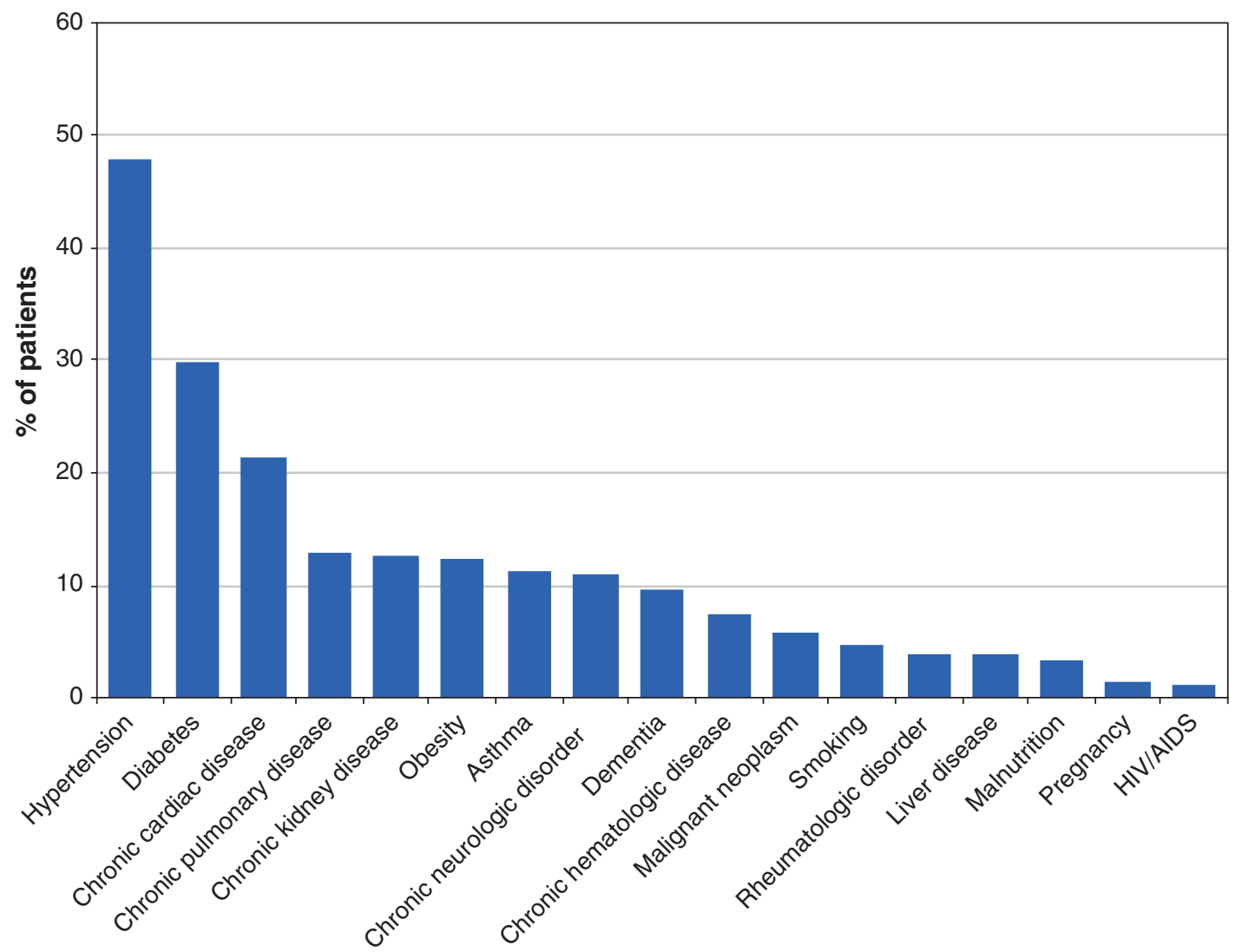

Condition present

Figure 2: Presenting comorbidities at admission among 811 patients admitted to hospital with coronavirus disease 2019.

Table 2: Interventions received among ward or critically ill patients with coronavirus disease 2019

\begin{tabular}{|lcc|}
\hline & & No. (\%) \\
\cline { 2 - 3 } Treatment & $\begin{array}{c}\text { Ward patients } \\
n=483\end{array}$ & $\begin{array}{c}\text { ICU patients } \\
n=328\end{array}$ \\
\hline Antibiotics & $357(73.9)$ & $283(86.3)$ \\
\hline Antiviral agent & $96(19.9)$ & $76(23.2)$ \\
\hline Systemic corticosteroids & $90(18.6)$ & $95(29.0)$ \\
\hline Oxygen & $274(56.7)$ & $328(100)$ \\
\hline High-flow nasal oxygen & $65(13.5)$ & $40(12.2)$ \\
\hline Noninvasive ventilation & $19(3.9)$ & $35(10.7)$ \\
\hline Invasive ventilation & - & $291(88.7)$ \\
\hline Prone ventilation & - & $55(16.8)$ \\
\hline Inotropes or vasopressors & - & $274(83.5)$ \\
\hline Renal replacement therapy & - & $49(14.9)$ \\
\hline ECMO & - & $13(4.0)$ \\
\hline Tracheostomy & - & $10(3.0)$ \\
\hline Note: ECMO = extracorporeal membrane oxygenation, ICU $=$ intensive care unit. & & \\
\hline
\end{tabular}




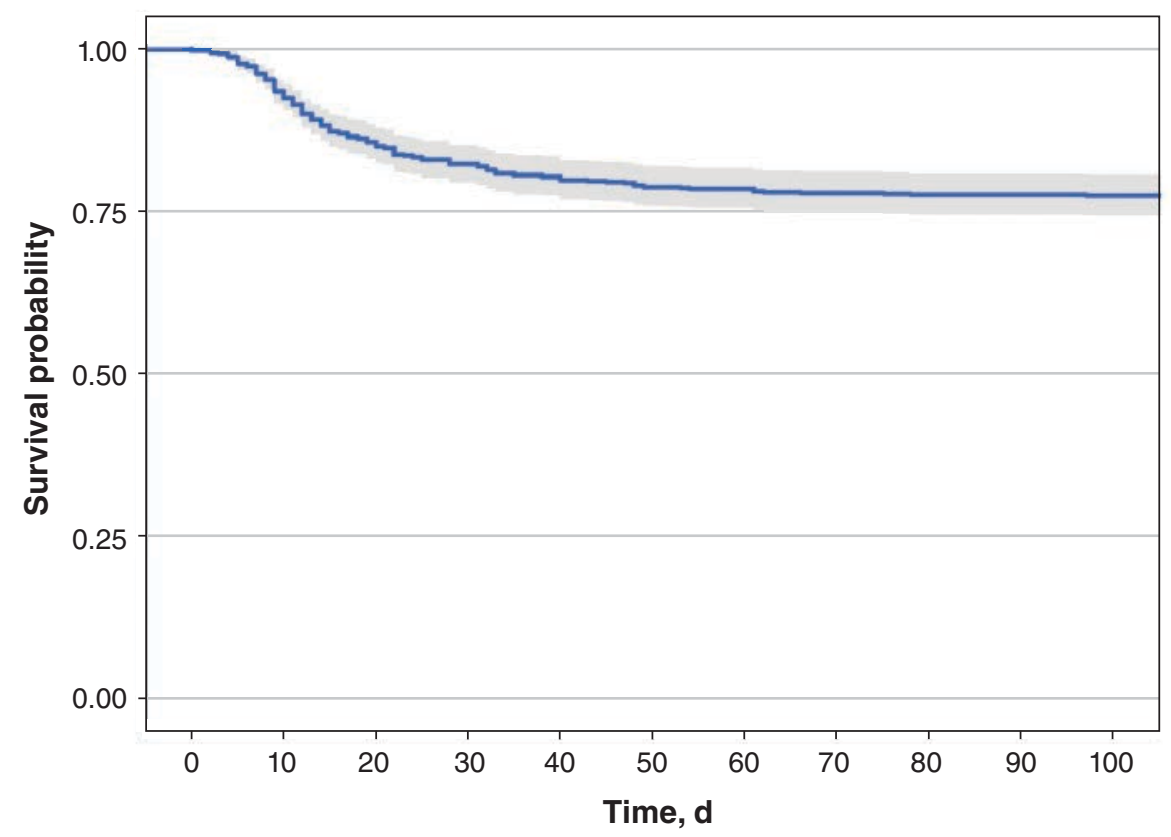

Figure 3: Time-to-event analysis for mortality. Shaded bars represent $95 \%$ confidence intervals.

Among patients admitted to the ICU, or those requiring mechanical ventilation, mortality was lower in our study than reported in many other countries in earlier phases of the pandemic. ${ }^{1,4}$ The reasons for this difference are not clear and might reflect differing demographic characteristics across studies, the impact of limited capacity for some elements of critical care during periods of greatest COVID19-related health system stress, differences in admission decisions or treatments, publication bias or other factors. The association of worse outcomes with older age has been previously shown; and differences in the ages of published cohorts may explain a high degree of variation in countrybased case-fatality rates. ${ }^{20}$ Comparing with previous years in the same data collection exercise, there was about a $10 \%$ mortality rate for ICU patients with severe acute respiratory infection. ${ }^{9}$ We were unable to capture the presence of donot-resuscitate or withdrawal of life-sustaining therapy orders and patient preferences, which may differ across the lifespan, and their impact on outcomes.

Less than $7 \%$ of patients presented without fever, shortness of breath, or fatigue or cough, similar to other cohorts. ${ }^{17}$ Standard screening practices focused on respiratory symptoms in hospitals in Canada are likely to remain relevant.

There were few children and pregnant women in this cohort. The small number of children is in keeping with findings elsewhere, where severe pediatric disease is relatively rare. Given the small numbers of children and pregnant women, we cannot make inferences about typical clinical characteristics or outcomes in these populations..$^{21}$ Large-scale international collaboration is required for a better understanding of the health effects on these groups.

There has been uncertainty regarding optimal methods of oxygenation and ventilation support for critically ill patients with COVID-19, which likely has influenced their infrequent use in this cohort. Uncertainty has surrounded the timing of intubation and mechanical ventilation, and the potential risk to health care workers in using noninvasive ventilation and high-flow nasal oxygen, stemming from concern of aerosolization and nosocomial amplification of SARS-CoV-2 transmission. ${ }^{22}$ We have not examined the association of specific medication or ventilation treatments with clinical outcomes owing to the inability to adequately adjust for confounding, immortal time and treatment indication bias in observational studies such as this one.

\section{Limitations}

The limitations of this study include the scope and granularity of data collected, and the sampling strategies. The study was meant to be rapidly deployed, scalable and operational at sites with varying research infrastructure, and we have collected a minimal clinical data set across Canadian hospitals. This has allowed SPRINT-SARI to continue without prepandemic funding, minimizing the data collection burden at individual sites. We have not reported laboratory data in this report owing to a large degree of missing data, limiting analysis. Some uncertainty will exist on long-term outcomes, which are better characterized through population-level studies, as some patients have not had their final outcome 
Table 3: Characteristics of patients with coronavirus disease 2019 who died or survived*

\begin{tabular}{|c|c|c|c|}
\hline \multirow[b]{2}{*}{ Characteristic } & \multicolumn{2}{|c|}{ No. (\%)† } & \multirow[b]{2}{*}{$p$ value } \\
\hline & $\begin{array}{l}\text { Patients who survived } \\
\qquad n=625\end{array}$ & $\begin{array}{l}\text { Patients who died } \\
\quad n=166\end{array}$ & \\
\hline Age, yr, mean \pm SD & $50.4 \pm 25.6$ & $71.7 \pm 11.9$ & $<0.001$ \\
\hline \multicolumn{4}{|l|}{ Age, yr } \\
\hline$<18$ & $26(100)$ & 0 & \\
\hline 19-39 & $75(96.1)$ & $3(3.8)$ & \\
\hline $40-59$ & $180(88.2)$ & $24(11.7)$ & \\
\hline $60-79$ & $316(82.5)$ & $67(17.5)$ & \\
\hline$\geq 80$ & $48(40.0)$ & $72(60.0)$ & \\
\hline \multicolumn{4}{|l|}{ Sex } \\
\hline Female & $234(37.5)$ & $73(43.9)$ & 0.2 \\
\hline Male & $391(62.5)$ & $93(56.1)$ & \\
\hline \multicolumn{4}{|l|}{ Comorbidities } \\
\hline Hypertension & $264(73.1)$ & 97 (26.9) & \\
\hline Diabetes & 148 (72.9) & $55(27.1)$ & \\
\hline Chronic kidney disease & $68(66.6)$ & 34 (33.3) & \\
\hline Asthma & $67(74.4)$ & $23(25.6)$ & \\
\hline Smoking & $25(67.5)$ & $12(32.4)$ & \\
\hline Pregnancy & $12(100)$ & 0 & \\
\hline $\begin{array}{l}\text { Time from symptom onset to hospital } \\
\text { admission, } d \text {, mean } \pm \text { SD }\end{array}$ & $6.9 \pm 12.4$ & $3.9 \pm 16.3$ & 0.04 \\
\hline Length of stay in hospital, d, mean \pm SD & $15.9 \pm 20.1$ & $16.4 \pm 22.2$ & 0.8 \\
\hline
\end{tabular}

declared or may have died after discharge to a long-term care facility.

Symptom characterization was dependent on patient report or clinician charting - for example, the low rate of anosmia is likely in keeping with its lack of recognition early in the pandemic or in patients who were too sick to report it. More in-depth characterization of disease, of specific subgroups of patients, and of resource use will require more thorough data collection at each site, including risk-adjustment with standardized data. ${ }^{23}$ Sampling was via convenience sampling for hospitals, and quota sampling within hospitals, and may not be representative of the Canadian population, more broadly.

The lack of interprovincial prepandemic capacity for this work underscores the need for a national clinical characterization data infrastructure for hospital-admitted patients that is rapidly accessible for Canadian clinicians, researchers, public health officials and policy-makers to inform understanding of the baseline characteristics, risk factors for outcomes and hospital use, and for benchmarking of disease severity over waves of outbreaks and across different care systems. This system would have value in both the inter- and intrapandemic periods.

\section{Conclusion}

We report clinical characteristics and outcomes of 811 patients admitted to hospital during the first wave of the COVID-19 pandemic in Canada. These data are crucial to expand during future pandemic waves to understand the impact of COVID-19 on our hospitals, to identify areas for improvements in clinical management, and to allow for ongoing international and temporal comparisons of outcomes for patients with COVID-19.

\section{References}

1. Grasselli G, Zangrillo A, Zanella A, et al. Baseline characteristics and outcomes of 1591 patients infected with SARS-CoV-2 admitted to ICUs of the Lombardy region, Italy. $7 A M A$ 2020;323:1574-81.

2. Bhatraju PK, Ghassemieh BJ, Nichols M, et al. Covid-19 in critically ill patients in the Seattle region - case series. N Engl f Med 2020;382: 2012-22.

3. Richardson S, Hirsch JS, Narasimhan M, et al. Presenting characteristics, comorbidities, and outcomes among 5700 patients hospitalized with COVID-19 in the New York City area. FAMA 2020;323:2052-9.

4. Armstrong RA, Kane AD, Cook TM. Outcomes from intensive care in patients with COVID-19: a systematic review and meta-analysis of observational studies. Anaesthesia 2020;75:1340-9.

5. Goyal P, Choi JJ, Pinheiro LC, et al. Clinical characteristics of COVID-19 in New York City. N Engl 7 Med 2020;382:2372-4.

6. Yang X, Yu Y, Xu J, et al. Clinical course and outcomes of critically ill patients with SARS-CoV-2 pneumonia in Wuhan, China: a single-centered, retrospective, observational study. Lancet Respir Med 2020;8:475-81. 
7. Coronavirus disease (COVID-19): outbreak update. Ottawa: Public Health Agency of Canada; 2020. Available: www.canada.ca/en/public-health/services/ diseases/2019-novel-coronavirus-infection.html (accessed 2020 July 21).

8. Mitra AR, Fergusson NA, Lloyd-Smith E, et al. Baseline characteristics and outcomes of patients with COVID-19 admitted to intensive care units in Vancouver, Canada: a case series. CMA7 2020;192:E694-701.

9. SPRINT-SARI Investigators. Using research to prepare for outbreaks of severe acute respiratory infection. BM7 Glob Health 2019;4:e001061.

10. Murthy S, Carson G, Horby P, et al. Clinical research networks and assessing pandemic severity. Lancet Glob Health 2019;7:e33.

11. Cao B, Wang Y, Wen D, et al. A trial of lopinavir-ritonavir in adults hospitalized with severe COVID-19. N Engl 7 Med 2020;382:1787-99.

12. Cummings MJ, Baldwin MR, Abrams D, et al. Epidemiology, clinical course, and outcomes of critically ill adults with COVID-19 in New York City: a prospective cohort study. Lancet 2020;395:1763-70.

13. Lescure FX, Bouadma L, Nguyen D, et al. Clinical and virological data of the first cases of COVID-19 in Europe: a case series. Lancet Infect Dis 2020;20:697-706.

14. COVID-19 clinical research resources. Oxford (UK): International Severe Acute Respiratory and Emerging Infection Consortium; 2020. Available: https://isaric.tghn.org/covid-19-clinical-research-resources (accessed 2020 Oct. 18).

15. R Core Team. R: A language and environment for statistical computing. Vienna (AU): R Foundation for Statistical Computing; 2020.

16. Gupta S, Hayek SS, Wang W, et al.; STOP-COVID Investigators. Factors associated with death in critically ill patients with coronavirus disease 2019 in the US. FAMA Intern Med 2020 July 15;180 [Epub ahead of print]. doi: 10.1001/jamainternmed.2020.3596.

17. Zhou F, Yu T, Du R, et al. Clinical course and risk factors for mortality of adult inpatients with COVID-19 in Wuhan, China: a retrospective cohort study. Lancet 2020;395:1054-62.

18. Xie J, Wu W, Li S, et al. Clinical characteristics and outcomes of critically ill patients with novel coronavirus infectious disease (COVID-19) in China: a retrospective multicenter study. Intensive Care Med 2020;46:1863-72.

19. Wendel Garcia PD, Fumeaux T, Guerci P, et al. Prognostic factors associated with mortality risk and disease progression in 639 critically ill patients with COVID-19 in Europe: initial report of the international RISC-19-ICU prospective observational cohort. EClinicalMedicine 2020;25:100449. doi: 10.1016/j.eclinm.2020.100449.

20. Sudharsanan N, Didzun O, Bärnighausen T, et al. The contribution of the age distribution of cases to COVID-19 case fatality across countries. Ann Intern Med 2020 July 22 [Epub ahead of print].

21. Docherty AB, Harrison EM, Green CA, et al. Features of 20133 UK patients in hospital with COVID-19 using the ISARIC WHO Clinical Characterisation Protocol: prospective observational cohort study. BM7 2020;369:m1985.

22. Agarwal A, Basmaji J, Muttalib F, et al. High-flow nasal cannula for acute hypoxemic respiratory failure in patients with COVID-19: systematic reviews of effectiveness and its risks of aerosolization, dispersion, and infection transmission. Can 7 Anaesth 2020;67:1217-48.

23. Knight SR, Ho A, Pius R, et al. Risk stratification of patients admitted to hospital with covid-19 using the ISARIC WHO Clinical Characterisation Protocol: development and validation of the 4C Mortality Score. BMF 2020;370: m3339.

Competing interests: Todd Lee reports salary support from Fonds de recherche du Québec - Santé. Deepali Kumar reports grants and personal fees from Roche. Michelle Kho reports grants from Canada Research Chairs. Matthew Cheng reports grants from the McGill Interdisciplinary Initiative in Infection and Immunity and personal fees from GEn1E Lifesciences (as a member of the scientific advisory board) and personal fees from nplex biosciences (as a member of the scientific advisory board). Philippe Jouvet reports consulting for Mallinckrodt Pharmaceuticals and grants to his institution from VitalTracer and Evolucare. Patrick Archambault is a co-investigator in the Canadian Institutes of Health Research (CIHR)-funded Canadian COVID-19 Emergency Department Rapid Response Network (https://canadiancovid19ednetwork.org). No other competing interests were declared.

Affiliations: Division of Infectious Diseases, Department of Medicine (Lee), McGill University, Montréal, Que.; Ajmera Transplant Centre (Kumar), University Health Network, Toronto, Ont.; Department of Critical Care Medicine (Dechert), Brantford General Hospital, Brantford, Ont.; Department of Medicine (Sandhu), St. Michael's Hospital, Toronto, Ont.; School of Rehabilitation Science (Kho, O'Grady), McMaster University, Hamilton, Ont.; St. Joseph's Healthcare (Kelly), Hamilton, Ont.; Island Health Authority (Ovakim), Victoria, BC;
Department of Anesthesiology and Department of Medicine - Critical Care Division (Carrier), Centre hospitalier de l'Université de Montréal, Montréal, Que.; Department of Medicine (Daneman), Sunnybrook Health Sciences Centre, University of Toronto, Toronto, Ont.; Faculté de médecine de l'Université de Montréal (Tessier-Grenier), Université de Montréal, Montréal, Que.; Vancouver Island Health Authority (Wood), Victoria, BC; Department of Medicine (Gu), McGill University, Montréal, Que.; Children's Hospital of Eastern Ontario Research Institute (O'Hearn), Ottawa, Ont.; Department of Community Health Sciences (Stelfox), University of Calgary, Calgary, Alta.; UBC Faculty of Medicine (Douglas), University of British Columbia, and Island Health, Vancouver, BC; Department of Medicine (Fowler), University of Toronto, Toronto, Ont.; Faculty of Medicine (Solomon), McGill University, Montréal, Que.; Department of Pediatrics (Goco) and of Critical Care Medicine (Guerguerian), The Hospital for Sick Children, Toronto, Ont.; Department of Medicine (Hsu), McGill University, Montréal, Que.; Divisions of Infectious Diseases and Medical Microbiology (Cheng), McGill University Health Centre, Montréal, Que.; Department of Medicine (Swanson), University of Victoria, Victoria, BC; Department of Medicine (Hall), Dalhousie University, Halifax, NS; Department of Medicine (Pitre), McMaster University, Hamilton, Ont.; Department of Pediatrics (Jouvet), Sainte-Justine Hospital, Université de Montréal, Montréal, Que.; Ottawa Hospital Research Institute (Pharand), Ottawa, Ont.; Department of Critical Care Medicine (Fiest), Cumming School of Medicine, University of Calgary, Calgary, Alta.; Faculty of Medicine, University of British Columbia, and Island Health (Reel), Victoria, BC; Department of Medicine (Tsang), McMaster University, Hamilton, Ont., and Niagara Health (Tsang), St. Catharines, Ont.; Grand River Hospital (Kruisselbrink), Kitchener, Ont.; Department of Family Medicine and Emergency Medicine (Archambault), Université Laval, Laval, Que.; Department of Medicine (Rishu), Sunnybrook Health Sciences Centre, Toronto, Ont.; Department of Medicine (Codan), University of Calgary, Calgary, Alta.; Departments of Medicine (Rewa, Sligl), of Critical Care Medicine (Kutsogiannis) and of Pediatrics (Joffe), University of Alberta, Edmonton, Alta.; Department of Medicine (Shadowitz), Sunnybrook Health Sciences Centre, Toronto, Ont.; Department of Medicine (Sarfo-Mensah), The Ottawa Hospital/Ottawa Hospital Research Institute, Ottawa, Ont.; Department of Medicine (Lamontagne), Université de Sherbrooke, Sherbrooke, Que.; Department of Pediatrics (Menon), University of Ottawa, Ottawa, Ont.; McGill University Health Centre (Atique), Montréal, Que.; William Osler Health System (Richardson), Toronto, Ont.; Joseph Brant Hospital (Reeve), Burlington, Ont.; Department of Pediatrics (Murthy), University of British Columbia, Vancouver, BC

Contributors: All authors contributed to the design of the project, revised the product, gave final approval for the published version, and agree to be accountable for all aspects of the work.

Funding: This work was supported by the Canadian Institutes of Health Research Canadian 2019 Novel Coronavirus (COVID-19) Rapid Research Funding Opportunity (OV2170359).

Content licence: This is an Open Access article distributed in accordance with the terms of the Creative Commons Attribution (CC BY-NC-ND 4.0) licence, which permits use, distribution and reproduction in any medium, provided that the original publication is properly cited, the use is noncommercial (i.e., research or educational use), and no modifications or adaptations are made. See: https://creativecommons.org/licenses/ by-nc-nd/4.0/

Data sharing: All data used for this project are available for analysis on request and relevant approvals. See iddo.org for further details.

Acknowledgements: The authors thank Mark Duffett and Neill Adhikari for critically reviewing this article. The authors also thank Shirin Tabrizi and Anjellica Chen for substantial contributions to the acquisition of data.

Supplemental information: For reviewer comments and the original submission of this manuscript, please see www.cmajopen.ca/content/9/1/ E181/suppl/DC1. 